\title{
A ética no ensino superior na área da saúde: uma revisão integrativa
}

Viviane Knuppel de Quadros Gerber ${ }^{1}$, Ivete Palmira Sanson Zagonel ${ }^{2}$

\section{Resumo}

Revisão integrativa com o objetivo de analisar como a ética no ensino superior na área da saúde é abordada na literatura, desenvolvida no período de janeiro de 2006 a dezembro de 2011, mediante pesquisa realizada nas bases SciELO e PubMed. Doze artigos preencheram os critérios de inclusão e as áreas com maior destaque foram Medicina (6), Odontologia (3) e Enfermagem (2), um deles publicado em conjunto com a área de Serviço Social, e um artigo sobre Saúde Pública. Por meio da análise de conteúdo, foram eleitas duas categorias temáticas: métodos e estratégias de ensino e avaliação da aprendizagem da ética. A análise indicou que as questões envolvidas no ensino-aprendizagem da ética são complexas e incluem incertezas e diversidade de opiniões e valores morais. Os alunos devem trabalhar com o tema em disciplinas com abordagem transversal, oportunidade de trocar ideias e refletir sobre as questões.

Palavras-chave: Ensino. Ética. Saúde.

\section{Resumen}

\section{Ética en la educación superior em salud: una revisión integrativa}

Revisión integrativa con el fin de realizar el análisis de cómo la ética en la educación superior en salud se aborda en la literatura desde enero 2006 hasta diciembre de 2011, a través de la investigación realizada en la base de datos PubMed y SciELO. Doce artículos cumplieron los criterios de inclusión y las áreas con mayor énfasis en las publicaciones fueron Medicina (6), Odontología (3) Enfermería (2), incluyendo uno de ellos publicado conjuntamente con el área de Servicios Sociales y un artículo en Salud Pública. A través del análisis de contenido, se eligieron dos categorías temáticas: métodos y estrategias para la enseñanza y la evaluación del aprendizaje de la ética. El análisis indicó que las cuestiones relacionadas con la enseñanza-aprendizaje de la ética son complejas e incluyen las incertidumbres y la diversidad de opiniones y valores morales. Los estudiantes deben trabajar con el tema en las disciplinas con enfoque transversal como una oportunidad para intercambiar ideas y reflexionar sobre estas cuestiones.

Palabras-clave: Enseñanza. Ética. Salud.

\begin{abstract}
Ethics in health college education area: an integrative review

Integrative review aiming to perform the analysis of how ethics in health higher education is addressed in the literature from January 2006 to December 2011, through research conducted in the SciELO and PubMed database. Twelve papers met the inclusion criteria: Medicine (6), Dentistry (3) Nursing (2) which were the areas with more emphasis on the publications, including one published in the area of Social Service and one Public Health article. Through content analysis, it was elected two thematic categories: Methods and Teaching Strategies and Ethics Learning Evaluation. The analysis indicated that the issues involved in the ethics teaching and learning are complex and include uncertainties and diversity of opinions and moral values. Students should work with the subject in disciplines with cross-cutting approach as an opportunity to exchange ideas and reflect on the issues.
\end{abstract}

Key words: Teaching. Ethics. Health.

1. Mestre vivianekg@yahoo.com.br - Universidade Estadual do Centro-Oeste, Guarapuava/PR, Brasil 2. Doutora ivete.zagonel@fpp. edu.br - Faculdades Pequeno Príncipe, Guarapuava/PR, Brasil.

Correspondência

Viviane Knuppel de Quadros Gerber - Rua 17 de Julho, 1.194 Trianon CEP 85012-040. Guarapuava/PR, Brasil.

Declaram não haver conflito de interesse. 
A ética é o estudo da conduta e do caráter. Relaciona-se com a determinação sobre o que é bom ou valioso para os indivíduos, grupos de indivíduos e a sociedade em geral. Atos considerados éticos refletem compromisso com padrões além das preferências pessoais - padrões que indivíduos, profissões e sociedades empenham-se em alcançar ${ }^{1}$.

A ética profissional ou deontologia compila, para os profissionais, os princípios orientadores em sua interação com pacientes, com outros profissionais e com as instituições onde trabalham ${ }^{2}$. Ética e moral são termos complementares. Ética, do grego ethos, significa "modo de ser", "caráter". Moral, do latim mor ou moris, significa "costume", ou seja, um conjunto de normas ou regras adquiridas pelo ser humano por uso ordinário ${ }^{3-4}$.

Nas relações profissionais a ética consubstancia-se mediante a responsabilidade, o compromisso com o trabalho e com o outro, bem como pelo respeito e afetividade às pessoas. Para tanto, a ética se desenvolve na formação profissional quando atitudes, valores e habilidades são construídos no exercício dessa prática profissional ${ }^{5}$.

$\mathrm{Na}$ área da saúde, a competência ética dos futuros profissionais é entendida como a capacidade autônoma de percepção, reflexão crítica e decisão coerente em relação às condutas humanas no cuidado à saúde e à vida. $O$ desenvolvimento dessa competência requer docentes capacitados e dispostos a assumir a discussão de aspectos relativos à prática educativa, de modo a favorecer uma formação centrada no educando e qualificada para a sociedade que subsidia e depende dessa formação ${ }^{6}$ - isso exige que os próprios docentes desenvolvam competências como a crítica e a reflexão.

No cenário de mudanças nos direitos humanos e nas ciências, surge a bioética. No entanto, segundo Pessini, quem primeiro utilizou o neologismo bioética foi Fritz Jahr, em 1927, na Alemanha. Jahr ampliou o imperativo categórico kantiano e propôs o imperativo bioético: respeite todo ser vivo como princípio e fim em si mesmo e trate-o, se possivel, enquanto tal. O lançamento da obra Fritz Jahr and the foundations of global bioethics: the future of integrative bioethics no VIII Congresso Internacional de Bioética Clínica, realizado em 2012 em São Paulo, constitui fato histórico de alcance mundial nessa incursão em relação aos primórdios da bioética ${ }^{7}$.

Segundo Van Resselaer Potter, a bioética se configura como a ética da sobrevivência, da vida e do ser vivo ${ }^{8}$. Caracteriza-se por seus aspectos filosóficos, científicos e sociopolíticos. Em seu surgimento estiveram presentes o avanço tecnológico e dos direitos individuais, a influência do multiculturalismo na sociedade e as mudanças na relação médico-paciente. Esta nova abordagem da ética se relaciona à complexidade e à possibilidade de abertura para contribuições de diversas disciplinas e discussão mais ampla com a sociedade ${ }^{\text {. }}$.

Numerosas mudanças sociais, éticas, econômicas e políticas vêm sendo observadas em âmbito mundial, que, de forma incisiva, têm atingido os sistemas de saúde. Intensificou-se, então, o enorme desafio de sua condução, tanto para os responsáveis envolvidos com o planejamento e a atenção em saúde como para as instituições que formam recursos humanos para o setor ${ }^{10}$. As instituições de formação, responsáveis pela profissionalização, precisam adequar-se para que o conhecimento que passam ao alunado seja condizente com soluções aos novos paradigmas sociais, éticos e econômicos que surgem no processo de construção do sistema de saúde ${ }^{11}$.

A educação ética embasada somente em discussões conceituais não é suficiente para formar os profissionais que o momento atual exige. Um novo paradigma em saúde se estabeleceu na América Latina e tem-se discutido intensivamente a necessidade de mudança nas metodologias de formação dos profissionais de saúde. Esse novo modelo de saúde exige novos sujeitos sociais, novas formas de prestação de serviços e novas maneiras de formar os profissionais da área ${ }^{12}$.

Tradicionalmente, o ensino da ética nas escolas de enfermagem brasileiras tem se caracterizado por uma visão deontológica, determinada por orientações prescritivas e normativas, restritas a um conjunto de normas e códigos trabalhados teórica e abstratamente ${ }^{13-14}$. O perfil desejado dos egressos dos cursos de graduação em enfermagem, no Brasil, remete a um profissional capaz de intervir nos serviços de saúde de baixa, média e alta complexidade. Por um lado, a tecnociência centrada nos hospitais e nos centros de diagnóstico de alta complexidade; por outro, a fome, a miséria, a injustiça, a corrupção política, a alocação de recursos e a distribuição dos serviços de saúde colocam o enfermeiro em um contexto dicotomizado, que dele exige senso crítico para tomar decisões éticas e morais ${ }^{15}$.

Desde 1990, o tema ética médica tem se tornado parte integral do currículo básico na maioria das escolas médicas nos países ocidentais. Contudo, a inclusão formal de ética médica no currículo médico resultou no surgimento de uma variedade de programas sobre ética com objetivos diversos e 
utilização de métodos variados. A apresentação e os métodos de avaliação em ética podem variar muito entre os programas de graduação de medicina, inclusive em um mesmo país ${ }^{16-18}$.

No currículo do curso médico de algumas universidades brasileiras, em seu formato tradicional, a bioética é incluída como disciplina voltada a orientar a aquisição de habilidades que permitam ao aluno identificar e analisar problemas éticos. Mas apenas alguns destes temas estão incluídos nas disciplinas de Medicina Legal e Deontologia, as quais, em geral, priorizam o Código de Ética Médica (CEM) e os aspectos legais da prática médica. Talvez esses conteúdos não sejam suficientes para satisfazer as necessidades dos alunos relativas aos conflitos éticos com os quais irão se deparar na prática acadêmica e em sua futura vida profissional ${ }^{19}$.

Assim, este estudo objetivou realizar o levantamento de como a ética no ensino superior na área da saúde é abordada na literatura, por meio de revisão integrativa.

\section{Método}

Trata-se de revisão integrativa de artigos científicos sobre o ensino da ética na educação superior na área da saúde. A revisão integrativa permite ao leitor reconhecer os profissionais que mais investigam determinado assunto, separar o achado científico de opiniões e ideias, além de descrever o conhecimento no seu estado atual, promovendo impacto sobre a prática clínica. Esse método de pesquisa proporciona aos profissionais de saúde dados relevantes acerca de determinado assunto, em diferentes lugares e momentos, mantendo-os atualizados e facilitando as mudanças na prática clínica como consequência da pesquisa ${ }^{20}$.

A revisão integrativa trabalha com evidências. Por isso, nas buscas de divulgação científica, optouse por consultar a Biblioteca Virtual em Saúde utilizando as bases de dados SciELO (Scientific Electronic Library Online) e PubMed. Foram selecionados artigos publicados no período de janeiro de 2006 a dezembro de 2011. Como descritores, foram utilizados: ensino, ética e saúde.

Na primeira fase, realizou-se a leitura dos títulos dos artigos e, para esclarecer eventuais dúvidas, alguns resumos. As publicações selecionadas obedeceram aos seguintes critérios de inclusão: artigos nos idiomas português, inglês e espanhol, completos; relação direta com os descritores; ser de domínio público; estar disponíveis online e pu- blicados nos anos 2006 a 2011. Excluídos os artigos que não preencheram esses critérios, foram encontrados 607 artigos na base de dados PubMed e 32, na SCIELO.

Após a aplicação dos critérios de inclusão, foram selecionados 12 artigos, classificados em relação à data de publicação, título do periódico e área de produção. Utilizou-se a técnica da análise de conteúdo temática, que consiste em operações de desmembramento do texto em unidades (categorias), segundo reagrupamentos analógicos ${ }^{20}$. A análise é feita em múltiplas fases que compreendem a ordenação dos dados; a leitura ou leitura flutuante, que é o estabelecimento de contato com os documentos da coleta de dados, momento de conhecer o conteúdo mediante o contato com a matéria; a classificação dos dados, pela constituição do corpus da organização analítica identificado por meio da exploração e categorização dos materiais; o tratamento dos resultados obtidos e a interpretação ${ }^{21}$.

\section{Resultados e discussão}

De acordo com os resultados, a área com maior número de publicações foi a de Medicina, com seis artigos (50\%), seguida por Odontologia, com três (25\%), Enfermagem, com dois (16,6\%), sendo um deles elaborado em conjunto com a área de Serviço Social, e um artigo $(8,3 \%)$ sobre programa de mestrado em Saúde Pública - o que indica que, mesmo não abundantes, estudos e pesquisas são realizados sobre o tema nas profissões de saúde.

Este dado vai ao encontro dos achados de pesquisa que avaliou o ensino da ética nos cursos de saúde por meio de revisão integrativa realizada de janeiro de 1997 a janeiro de 2009, na qual se identificou que $73,08 \%$ das publicações eram relacionadas ao curso de Medicina. Os autores afirmaram que esse resultado se devia ao fato de que a medicina foi a primeira profissão a se estruturar na área da saúde e acompanhou os diversos questionamentos éticos pelos quais a ciência e a humanidade passaram ${ }^{21}$. De fato, o primeiro documento ético conhecido, o juramento de Hipócrates, foi escrito há mais de dois mil anos. Com isso, se entende que o tema tenha se aprofundado mais na medicina que nas outras profissões de saúde ${ }^{22}$.

O periódico com maior número de artigos selecionados foi o Journal of Medical Ethics, com três publicações; a seguir, a revista Ciência \& Saúde Coletiva, com duas. Os demais periódicos tiveram a frequência de um artigo por revista. A Tabela 1 relaciona a quantidade de artigos publicados por periódico. 
Tabela 1. Número de artigos selecionados por periódico de janeiro de 2006 a dezembro de 2011

\begin{tabular}{|c|c|c|}
\hline Periódico & $\begin{array}{l}\mathbf{N}^{\circ} \text { de } \\
\text { artigos }\end{array}$ & $\begin{array}{c}\text { Ano de } \\
\text { publicação }\end{array}$ \\
\hline $\begin{array}{l}\text { Journal of Medical } \\
\text { Ethics }\end{array}$ & 3 & 2007 \\
\hline $\begin{array}{l}\text { Ciência \& Saúde } \\
\text { Coletiva }\end{array}$ & 2 & 2009 e 2011 \\
\hline $\begin{array}{l}\text { Revista Médica de } \\
\text { Chile }\end{array}$ & 1 & 2011 \\
\hline $\begin{array}{l}\text { Journal of Dental } \\
\text { Education }\end{array}$ & 1 & 2010 \\
\hline $\begin{array}{l}\text { Journal of Family \& } \\
\text { Comunity Medicine }\end{array}$ & 1 & 2010 \\
\hline $\begin{array}{l}\text { American Journal of } \\
\text { Bioethics }\end{array}$ & 1 & 2008 \\
\hline $\begin{array}{l}\text { Sociedade Brasileira } \\
\text { de Pesquisa } \\
\text { Odontológica }\end{array}$ & 1 & 2006 \\
\hline $\begin{array}{l}\text { Revista Brasileira de } \\
\text { Educação Médica }\end{array}$ & 1 & 2010 \\
\hline $\begin{array}{l}\text { Acta Paulista de } \\
\text { Enfermagem }\end{array}$ & 1 & 2006 \\
\hline Total & 12 & \\
\hline
\end{tabular}

Os anos de 2007 e 2010 contaram com três publicações cada, seguidos por 2011 e 2006 com duas publicações anuais e 2008 e 2009, com uma publicação cada. Para aprofundar a compreensão sobre o tema, foram eleitas duas categorias a partir das quais os materiais dos artigos foram analisados: métodos e estratégias de ensino e avaliação da aprendizagem da ética.

A Tabela 2, ao final, ilustra um resumo dos doze artigos selecionados para a confecção deste trabalho, trazendo o país de origem, nível de ensino abordado, se universidade pública ou privada, metodologia, objetivos e resultados de cada artigo.

\section{Método e estratégias de ensino}

Com relação aos achados da pesquisa, baseado nos doze artigos, os contextos, os conflitos de convivência e de trabalho devem ser o pano de fundo do ensino e da aprendizagem da ética, sobre o qual os alunos e professores estabelecem o diálogo. As experiências reais e diretas da vida coletiva e do processo de trabalho em saúde são os contextos em que o ensino e a aprendizagem da ética ocorrem de maneira mais eficaz. Por isso, é importante que se tenha um ambiente em que a ética e a prática da ética sejam realidade. Apesar da problematização e da aprendizagem baseada em problemas serem citadas como modelos de ensino eficazes, para a formação moral é preciso que os educadores fundamentem sua prática em determinada teoria de conhecimento. Não basta adotar metodologias e meios inovadores se o docente não tiver uma concepção pedagógica estruturada para fundamentar e direcionar sua prática educativa ${ }^{15}$.

A compreensão de que o conhecimento se concretiza por meio das representações mentais que o sujeito estabelece, a partir de sua relação com o objeto e deste com os outros objetos, nos leva a afirmar que a problematização, enquanto categoria de construção de conhecimento, é uma alternativa viável para o ensino da ética e da bioética. A problematização pressupõe experimentação, trabalho em grupo e pesquisa como elementos de provocação, de desafio, de significação para diversas atividades pedagógicas ${ }^{23}$.

O potencial da ética como eixo transversal na formação em saúde aplica-se especialmente no momento da crise do paradigma biomédico e na reestruturação curricular dos cursos de saúde. É importante investir na transdisciplinaridade das disciplinas do curso com o objetivo de colocar a serviço da sociedade profissionais que visem aprimorar, além de aptidões teórico-técnicas, o desenvolvimento de habilidades sociais e pessoais, incentivando a avaliação e o exercício da autocrítica permanentemente no processo natural das atividades de todas as disciplinas básicas e profissionais ${ }^{24}$.

Sobre a transversalidade do ensino da ética e da bioética, e partindo do princípio de que o objetivo desse ensino é o desenvolvimento moral do aluno, observa-se que uma única disciplina não consegue oferecer todos os recursos necessários para que tal meta seja atingida, pois se está falando de processo de longo prazo, complexo e abrangente. Uma das estratégias sugeridas para a inclusão do ensino dessas disciplinas na elaboração dos currículos é a abordagem transversal ${ }^{25-26}$, ou seja, diversas áreas curriculares devem planejar atividades voltadas à educação moral.

A educação para a formação ética ministrada de forma transversal, inserida em todas as disciplinas/módulos/unidades de um currículo, não exime os educadores de pensarem em metodologias específicas e estratégias de ensino que promovam a reflexão dialógica. A transversalidade do ensino da ética não pode restringir-se a atividades desordenadas e ocasionais. O currículo, em sua totalidade, precisa ser planejado para priorizar esse conhecimento/ 
habilidade do primeiro ao último ano: orientado por uma proposta suficientemente precisa e convenientemente sequenciada em função de objetivos e desempenhos a serem alcançados. É imprescindível, ainda, que haja conteúdos referentes a fatos vivenciados na vida profissional e articulados com o processo de trabalho, além de estímulo constante para que a práxis, procedimentos e valores ${ }^{25}$, esteja orientada por uma proposta de reflexão constante, inibindo a mecanização da atividade laboral.

Estudo realizado com o objetivo de investigar a relação entre ética e educação, por meio de levantamento da prática de enfermeiros e assistentes sociais, indicou que embora seja amplamente reconhecido que as questões éticas são onipresentes na área da saúde, apenas $57 \%$ dos enfermeiros e assistentes sociais entrevistados tiveram educação e treinamento em ética na graduação ou em programas de capacitação profissional de nível mais avançado (lato ou stricto sensu). Os dados desse estudo mostram que a educação e o treinamento em ética têm significativa influência sobre a confiança do profissional, proporcionando-lhe recursos para atuar com ética e moral ${ }^{27}$.

Na área médica, na qual o comportamento ético é discutido com mais frequência quando comparada com a área odontológica, as evidências indicam que atitudes eticamente inadequadas e desumanas são frequentemente observadas não apenas nos profissionais da clínica, mas também nos docentes. A inobservância de princípios éticos pode ser facilmente identificada em vários dos cenários de cuidados de saúde do sistema, incluindo-se as escolas médicas, estendendo-se às relações docente-docente, aluno-docente e relação médico-paciente ${ }^{28-29}$.

Embora esses dados possam causar preocupação, esse problema não é peculiar ao Brasil. Bioeticistas de vários países, incluindo-se Canadá, $\mathrm{Chi}$ le, Japão e Estados Unidos da América (EUA), concordam que, atualmente, a educação bioética não atende às necessidades das sociedades em seus países ${ }^{4,7-9}$. Embora a educação bioética não possa superar todas as irregularidades que venham a ocorrer na clínica e nas pesquisas envolvendo seres humanos, os programas de graduação devem valorizá-la de tal maneira que gere um impacto positivo na formação científica dos alunos ${ }^{30-32}$.

Assim, o ensino da bioética em programas de pós-graduação, especialmente na área odontológica, deve objetivar a formação de profissionais que, ao interagirem com seus colegas de trabalho, estejam familiarizados e capazes de utilizar os aspectos fundamentais do comportamento ético durante pesquisas clínicas com o uso de experimentos com animais e, acima de tudo, com seus pacientes e voluntários de pesquisa. Esse comportamento ético inclui a correta apresentação do termo de consentimento livre e esclarecido (TCLE) em toda pesquisa ${ }^{33}$.

Apesar de a importância do estudo da ética e da bioética ser identificada nos trabalhos analisados, não existe, no entanto, uma abordagem única para o ensino dessas disciplinas em nenhuma área da saúde e, especialmente, na odontologia ${ }^{34}$. No Kings College de Londres o ensino da ética e do direito é ministrado nos primeiros dois anos por meio de palestras e sessões de pequenos grupos ${ }^{35}$. Pesquisa realizada com o objetivo de descrever a abordagem didática usada para ensinar ética odontológica e raciocínio ético para estudantes do primeiro ano da Faculdade de Odontologia da Universidade de British Columbia salienta que a ética tem o seu lugar na educação odontológica como uma virtude esperada entre os alunos, que se tornarão profissionais licenciados e responsabilizados pelo público, governo e órgãos reguladores, bem como perante os colegas.

Os estudos afirmam que para responder às expectativas direcionadas ao período de formação do discente é indispensável tornar o estudo da ética experiencial e relevante para os alunos, o que constitui um desafio em si mesmo ${ }^{36}$. Workshops e discussões em pequenos grupos são realizados para que os alunos possam interagir, discutir, apresentar e defender suas convicções éticas ${ }^{37-38}$. Nesse contexto, o presente estudo verificou que a aprendizagem baseada em problemas também tem sido utilizada como meio eficaz para ensinar ética. Embora o ensino da ética odontológica não possa garantir a formação de dentistas éticos, os educadores dentários devem defender e trabalhar para melhorar o conteúdo da ética na educação odontológica ${ }^{39}$.

\section{Avaliação da aprendizagem da ética}

Neste estudo, dez artigos analisados avaliaram a aprendizagem da ética. Para as avaliações foram utilizados métodos como questionários, entrevistas e discussão de casos envolvendo situações de cunho ético, classificando os cursos e suas propostas pedagógicas para o ensino da ética e bioética de acordo com as respostas dos estudantes.

Os dados de pesquisa realizada com o objetivo de avaliar o ensino da bioética em programas brasileiros de pós-graduação em odontologia mostrou que $45 \%$ desses programas não oferecem qualquer tipo de ensino da bioética - percentagem alta, se 
comparada com estudos realizados nos EUA, onde o percentual de escolas de odontologia sem curso de bioética era de $21 \%$ quinze anos atrás ${ }^{39}$. Nesse contexto, os resultados do estudo sugerem que tal fato não constitui grande preocupação - o discutir bioética na formação do aluno de pós-graduação -, haja vista que apenas $52 \%$ e $65 \%$ das instituições públicas e privadas, respectivamente, tiveram bioética ou ética em seus programas de pós-graduação. Adicionalmente, apenas 38\% dos programas de pósgraduação com melhores avaliações (notas 5, 6 ou 7 na Comissão de Assessoramento de Pessoal de nível Superior/Capes) tiveram cursos de ética ou de bioética, enquanto $62 \%$ dos programas com avaliações piores (notas 3 e 4) tiveram ética ou curso de bioética. Desta forma, os resultados deste estudo representam um alerta para os educadores envolvidos em ensino da pesquisa odontológica. E também mostram que a instrução em bioética ainda é incipiente nos programas de pós-graduação em Odontologia no Brasil, apesar de a Resolução 196/96 do Conselho Nacional de Saúde ter sido publicada há dez anos. Por este motivo, seria necessário assegurar uma pedagogia ética na formação do jovem pesquisador ${ }^{40}$.

Na Arábia Saudita, em pesquisa com o objetivo de relatar a avaliação de um curso da disciplina de Ética Médica na graduação, os alunos participantes a avaliaram como assunto digno de estudo e compreensão, e não apenas para ser trabalhado pela perspectiva do senso comum. O estudo também revelou que a disciplina é importante para os professores, com vistas a atender a necessidade de formação dos futuros médicos, capacitando-os a lidar com dilemas éticos suscetiveis de ser confrontados com a prática clínica. A maior parte dos conteúdos do curso foi recomendada nos currículos. A maioria dos alunos participantes concordou que o conteúdo do curso foi relevante e em sintonia com sua cultura, mas significativa minoria discordou. O que pode dever-se ao fato de os estudantes não terem sido expostos à prática clínica ou a resultado de falha da faculdade para tratar o sujeito ${ }^{41}$.

Em pesquisa sobre o ensino da Ética Médica para alunos de graduação na África do Sul, encontrou-se que o curso ensina sobre o respeito pela pessoa e pela vida, com os pacientes e comunidade, e a agir com disposição leal e eticamente responsável com a profissão, buscando ainda alertar os estudantes para o reconhecimento das limitações do conhecimento e das próprias habilidades. Com vistas a que os alunos identifiquem os dilemas éticos que surgem na prática, e a sua resolução, os acadêmicos foram avaliados no exame de ética no quinto ano. Até o momento, em todas essas áreas, os alunos demonstraram boas habilidades para resolvê-los ${ }^{42}$.

Pesquisa em um curso de Medicina brasileiro corrobora esses achados ao apontar que o maior tempo de exposição aos conteúdos de ética aumenta a possibilidade de aprendizagem, considerando-se a quantidade de acertos entre o primeiro $(13,97 \%)$ e o sexto ano $(16,77 \%)$ em resposta a um questionário. Os autores informam, ainda, que não existe diferença significativa quando comparados diferentes modelos pedagógicos. Constatou-se nos resultados uma diferença entre média de acertos de $17,15 \%$ para estudantes do método tradicional e de $16,51 \%$ para o método de aprendizagem baseada em problemas ${ }^{43}$. Os resultados contrariam a afirmação de que a metodologia do curso pode influenciar a aprendizagem ética ${ }^{9}$.

Os estágios clínicos dos cursos do ensino superior da área da saúde representam para os docentes um momento importante, o de avaliar se o aluno tem a capacidade de aplicar o ensinado durante as aulas teóricas - no qual se exige a aplicação prática dos princípios de ética, analisando-se o comportamento do estudante com a profissão. Para que esses conteúdos sejam de fato assimilados e incorporados à prática do futuro profissional, precisam ser ministrados de maneira constante e progressiva ao longo do curso, apresentados em todas as disciplinas no intuito de promover a transdisciplinaridade e avaliados de maneira pertinente, considerando-se a ética e a bioética como focos legítimos da boa formação profissional.

\section{Considerações finais}

Realizou-se a análise de artigos de publicação nacional e internacional no período de janeiro de 2006 a dezembro de 2011, utilizando-se os descritores ensino, ética e saúde. Doze artigos estiveram acordes com os critérios de inclusão. Verificou-se que dentre as 14 profissões da área da saúde havia produções das profissões de Medicina, Odontologia, Enfermagem e Serviço Social. Houve o predomínio de publicações da área de Medicina, seguidas por Odontologia, Enfermagem, Serviço Social e um programa de mestrado em Saúde Pública.

A análise de conteúdo dos artigos indicou duas categorias temáticas. Na primeira, sobre métodos e estratégias de ensino, revelou a abordagem transversal para a inclusão do ensino da ética na elaboração dos currículos, ou seja, as diversas áreas curriculares devem planejar atividades para a educação 
moral. A segunda, referente à avaliação da aprendizagem, indicou diferentes formas de avaliação, que são utilizadas em cursos sobre a temática: exame da ética, workshops, discussões em pequenos grupos. Nessa categoria destacam-se a importância da prática clínica e o aumento do conhecimento sobre a ética relacionado ao tempo de curso do aluno.

As questões envolvidas no ensino-aprendizagem da ética são complexas e geralmente incluem incertezas e diversidade de opiniões e valores mo- rais. Os alunos devem trabalhar com o tema em disciplinas com abordagem transversal, com a oportunidade de trocar ideias e refletir sobre as questões.

Considerando-se as limitações do presente estudo, referentes aos critérios de inclusão, necessitase de investigações mais extensas e aprofundadas que acompanhem o estudante e o ensino da ética durante os cursos de graduação e pós-graduação, bem como levantem a percepção sobre a temática no âmbito profissional.

\section{Referências}

1. Potter P, Perry A. Fundamentos de enfermagem. $7^{\text {a }}$ ed. Rio de Janeiro: Elsevier; 2009.

2. Miller S. What use are ethical codes? An analysis of three possible rationales for the use of ethical cades in medical schools and a review of the evidence relating to them. Med Educ. [internet]. 2000 [acesso mar. 2012];34:428-9. Disponível: http:www3.interscience.wiley.com/cgibin/ fulltext/119010634/PDFSTART

3. Grisard N. Manual de orientação ética e disciplinar. Florianópolis: Cremesc; 2006.

4. Castilho EA, Kalil J. Ética e pesquisa médica: princípios, diretrizes e regulamentações. Rev Soc Bras Med Trop. 2005;38(4):344-7.

5. Alarcão I. Escola reflexiva e nova racionalidade. Porto Alegre: Artmed; 2001.

6. Finkler M, Campognara S, Reibnitz KS, Backe V, Caetano JC. Metodologias ativas no processo ensino-aprendizagem: possibilidade para uma prática educativa mais participativa na área da saúde. Abeno. 2008;8(2):140-5

7. Pessini L. Apresentação. In: Porto D, Garrafa V, Martins GZ, Barbosa SN, organizadores. Bioéticas, poderes e injustiças: 10 anos depois. Brasília: Conselho Federal de Medicina; 2012.

8. Durand G. Introdução geral à bioética: história, conceitos e instrumentos. São Paulo: Loyola; 2003.

9. Gomes AMA, Moura EREM, Amorim RF. O lugar da ética e bioética nos currículos de formação médica. Rev Bras Educ Med. [internet]. 2006 [acesso mar. 2012];20(2):56-65. Disponível: http:// www.scielo.br/pdf/rbem/v30n2/v30n2a08.pdf

10. Piancastelli $\mathrm{CH}$. Saúde da família e formação de profissionais de saúde. In: Arruda BKG, organizador. A educação profissional em saúde e a realidade social. Recife: Imip; 2001. p. 121-40.

11. Feuerwerker LCM. Além do discurso de mudança na educação médica: processos e resultados. São Paulo: Hucitec; 2002.

12. Almeida $M$, Feuerwerker $L$, Llanos $C M$, organizadores. A educação dos profissionais de saúde na América Latina: teoria e prática de um movimento de mudança. São Paulo: Hucitec; 1999.

13. Germano RM. A ética e o ensino de ética na enfermagem do Brasil. São Paulo: Cortez; 1993.

14. Gomes PC. Ética e enfermagem: relações ou reações? [tese]. São Paulo: Escola Paulista de Medicina da Universidade Federal de São Paulo; 1999.

15. Ferreira HM, Ramos LH. Diretrizes curriculares para o ensino da ética na graduação em enfermagem. Acta Paul Enferm. [internet]. 2006 [acesso mar. 2012];19(3):328-31. Disponível: http://www.scielo.br/pdf/ape/v19n3/a12v19n3.pdf

16. Goldie J. Review of ethics curricula in undergraduate medical education. Med Educ. 2000;34(2):108-9.

17. Teaching medical ethics and law within medical education: a model for the UK core curriculum. $J$ Med Ethics. 1998;24:188-92.

18. Bligh J, Mattick K. Undergraduate ethics teaching: revisiting consensus statement. Med Educ. 2006;40(4):329-32.

19. Pimentel D, Oliveira CB, Vieira MJ. Percepciones de los estudiantes acerca de la enseñanza de ética médica. Rev Med Chile. 2011;139(1):36-44.

20. Roman AR, Friedlander MR. Revisão integrativa de pesquisa aplicada a enfermagem. Cogitare Enferm. 1998;3(2):109-12.

21. Minayo MCS. O desafio do conhecimento: pesquisa qualitativa em saúde. $8^{a}$ ed. São Paulo: Hucitec; 2004.

22. Carneiro LA, Porto CC, Duarte SBR, Chaveiro N, Barbosa MA. O ensino da ética nos cursos de graduação da área de saúde. Rev Bras Educ Méd. 2010;34(3):412-21.

23. Diaz Bordenave J, Pereira AM. Estratégias de ensino-aprendizagem. $8^{\text {a }}$ ed. Petrópolis; Vozes: 1986.

24. Sá Jr. LSM. Ética do professor de medicina. Bioética. 2002;10(1):49-84. Disponível: http:// revistabioetica.cfm.org.br/index.php/revista_bioetica/article/view/198/201

25. Puig JM. Ética e valores: métodos para um ensino transversal. São Paulo: Casa do Psicólogo; 1998. 
26. Rego S. A formação ética dos médicos: saindo da adolescência com a vida (dos outros) nas mãos. Rio de Janeiro: Fiocruz; 2003.

27. Grady C, Danis M, Soeken KL, O'Donnell P, Taylor C, Adrienne F, Ulrich CM. Does ethics education influence the moral action of practicing nurses and social workers? Am J Bioeth. 2008;8(4):4-11.

28. Rego SA. Op. cit. p. 184.

29. Romano VF. O ensino-aprendizagem da relação médico-paciente no terceiro ano médico: o relato de uma observação. [dissertação]. Rio de Janeiro: Universidade Estadual do Rio de Janeiro; 2001.

30. Goldie J, Schwartz L, McConnachie A, Morrison J. The impact of three years' ethics teaching, in an integrated medical curriculum, on students' proposed behaviour on meeting ethical dilemmas. Med Educ. 2002;36(5):489-97.

31. Odom JG. Formal ethics instruction in dental education. J Dent Educ. 1982;46(9):553-7.

32. Piko BF, Kopp MS. Paradigm shifts in medical and dental education: behavioral sciences and behavioral medicine. Eur J Dent Educ. 2004;8(Supl 4):25-31.

33. Conselho Nacional de Saúde (Brasil). Resolução n 196, de 10 de outubro de 1996. [internet]. Aprova as diretrizes e normas regulamentadoras de pesquisas envolvendo seres humanos. Brasília: Ministério da Saúde/Conselho Nacional de Saúde; 1996 [acesso mar. 2012]. Disponível: http://conselho.saude.gov.br/resolucoes/1996/Reso196.doc

34. Ardenghi DM. Dentists' ethical practical knowledge: a critical issue for dental education. Eur J Dent Educ. 2009;13(2):69-72.

35. Mattick K, Bligh J. Teaching and assessing medical ethics: where are we now? J Med Ethics. 2006;32(3):181-5.

36. Brondani MA, Rossoff LP. The "hot seat" experience: a multifaceted approach to the teaching of ethics in a dental curriculum. J Dent Educ. 2010;74(11):1220-9.

37. Berk NW. Teaching ethics in dental schools: trends, techniques, and targets. Dent J Educ. 2001;65(8):744-50.

38. Dibbern DA. Workshop-based learning: a model for teaching ethics. Jama. 1995;274(9):770-1.

39. Mumma RD. The dental education perspetives. J Am Coll Dent. 1990;57(3):14-6.

40. Aires CP, Hugo FN, Rosalen PL, Marcondes FK. Ensino de bioética em programas de pós-graduaçăo em odontologia no Brasil. Braz Oral Res. 2006;20(4):285-9.

41. Al-Haqwie Al, Al-Shehri AM. Medical students' evaluation of their exposure to the teaching of ethics. J Family Community Med. 2010;17(1):41-5.

42. Moodley K. Teaching medical ethics to undergraduate students in post-apartheid South Africa, 2003-2006. J Med Ethics. 2007;33(11):673-7.

43. Figueira EJG, Cazzo E, Tuma P, Silva Filho CR, Conterno LO. Apreensão dos tópicos de ética médica no ensino-aprendizagem de pequenos grupos. Comparando aprendizagem baseada em problemas com o modelo tradicional. Rev Assoc Med Bras. [internet]. 2004 [acesso mar. 2012];50(2):133-41. Disponível: http://www.scielo.br/pdf/ramb/v50n2/20772.pdf

Participação dos autores no artigo

Todos os autores participaram da construção do artigo, coleta, análise e síntese das informações.

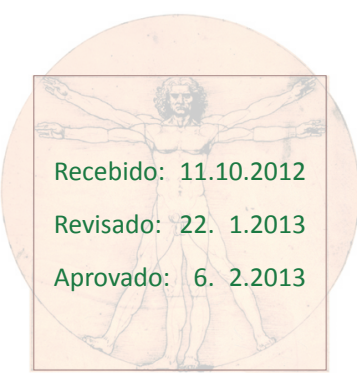


Tabela 2. Resumo das características dos artigos selecionados

\begin{tabular}{|c|c|c|c|c|c|c|}
\hline Art. & País & $\begin{array}{l}\text { Nível de } \\
\text { ensino }\end{array}$ & $\begin{array}{c}\text { Universi- } \\
\text { dade }\end{array}$ & Metodologia & Objetivos & Resultados \\
\hline 1 & Brasil & Graduação & Pública & $\begin{array}{l}\text { Qualitativa, } \\
\text { estudo des- } \\
\text { critivo }\end{array}$ & $\begin{array}{c}\text { Delinear } \\
\text { panorama da } \\
\text { formação éti- } \\
\text { ca nos cursos } \\
\text { brasileiros de } \\
\text { odontologia }\end{array}$ & $\begin{array}{l}\text { Apontou comprometimento pon- } \\
\text { tual dos cursos de odontologia } \\
\text { com a dimensão ética da forma- } \\
\text { ção profissional e indicou defi- } \\
\text { ciências quanto aos conteúdos } \\
\text { relacionados à formação cultural, } \\
\text { humanística e política. }\end{array}$ \\
\hline 2 & Brasil & Graduação & Pública & $\begin{array}{l}\text { Qualitativa, } \\
\text { transversal } \\
\text { analítica, } \\
\text { observacio- } \\
\text { nal }\end{array}$ & $\begin{array}{c}\text { Avaliar a per- } \\
\text { cepção de } \\
\text { estudantes } \\
\text { de medicina } \\
\text { da universi- } \\
\text { dade sobre } \\
\text { conflitos } \\
\text { éticos }\end{array}$ & $\begin{array}{l}\text { Observou que o ensino da ética é } \\
\text { pouco explorado na universidade, } \\
\text { apesar de sua grande importân- } \\
\text { cia. Concluiu pela necessidade de } \\
\text { maior compromisso com a edu- } \\
\text { cação focada na humanização da } \\
\text { prática médica, com professores } \\
\text { mais preparados, melhor infraes- } \\
\text { trutura e reforma curricular prio- } \\
\text { rizando o ensino da ética. }\end{array}$ \\
\hline 3 & Canadá & Graduação & $\begin{array}{l}\text { Pública } \\
\text { (Univer- } \\
\text { sidade } \\
\text { de British } \\
\text { Columbia) }\end{array}$ & Qualitativa & \begin{tabular}{|} 
Descrever \\
abordagem \\
didática uti- \\
lizada para \\
ensinar ética \\
no curso de \\
odontologia
\end{tabular} & $\begin{array}{l}\text { Conclui pela necessidade de mais } \\
\text { debates para melhor "compreen- } \\
\text { der as implicações das questões } \\
\text { éticas" nos ambientes acadêmico } \\
\text { e profissional. Indica que o ensino } \\
\text { de ética dentária não deve ser } \\
\text { limitado a uma única disciplina ou } \\
\text { a um ano. Para que seja signifi- } \\
\text { cativo o raciocínio ético deve ser } \\
\text { reforçado, integrado e aplicado a } \\
\text { todo o currículo do curso, durante } \\
\text { todos os anos. }\end{array}$ \\
\hline 4 & $\begin{array}{l}\text { Arábia } \\
\text { Saudita }\end{array}$ & Graduação & Pública & $\begin{array}{c}\text { Qualitativa, } \\
\text { por meio de } \\
\text { questionários } \\
\text { aplicados aos } \\
\text { estudantes } \\
\text { de medicina }\end{array}$ & \begin{tabular}{|c|} 
Explorar a \\
percepção \\
dos estudan- \\
tes de medi- \\
cina sobre os \\
módulos do \\
curso \\
\end{tabular} & $\begin{array}{l}\text { Todos os alunos defenderam a } \\
\text { importância da aprendizagem éti- } \\
\text { ca, incluindo o desenvolvimento } \\
\text { profissional, avaliação de compe- } \\
\text { tências éticas e o ensino da ética. }\end{array}$ \\
\hline 5 & Brasil & Graduação & Privada & Qualitativa & $\begin{array}{c}\text { Analisar a } \\
\text { percepção } \\
\text { dos alunos } \\
\text { de medicina } \\
\text { sobre as rela- } \\
\text { ções éticas } \\
\text { envolvidas } \\
\text { nas ações } \\
\text { em saúde na } \\
\text { comunidade }\end{array}$ & 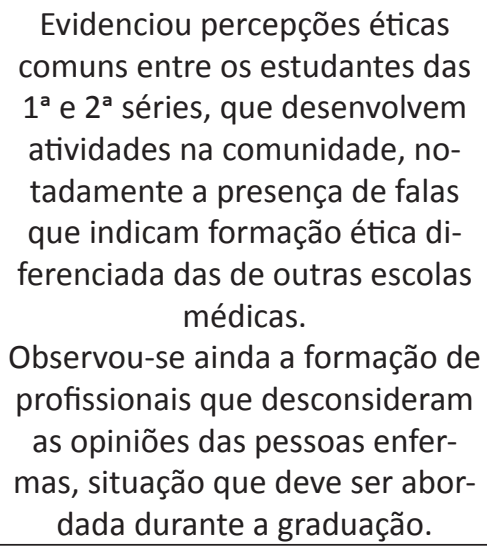 \\
\hline
\end{tabular}




\begin{tabular}{|c|c|c|c|c|c|c|}
\hline Art. & País & $\begin{array}{l}\text { Nível de } \\
\text { ensino }\end{array}$ & $\begin{array}{l}\text { Universi- } \\
\text { dade }\end{array}$ & Metodologia & Objetivos & Resultados \\
\hline 6 & EUA & $\begin{array}{l}\text { Assistentes } \\
\text { sociais e } \\
\text { enfermeiros }\end{array}$ & $\begin{array}{l}\text { Pública } \\
\text { (Centro de } \\
\text { Pesquisa } \\
\text { da Univer- } \\
\text { sidade da } \\
\text { Virgínia) }\end{array}$ & $\begin{array}{l}\text { Questioná- } \\
\text { rios únicos } \\
\text { para ambos } \\
\text { os grupos } \\
\text { profissionais; } \\
\text { análise esta- } \\
\text { tística }\end{array}$ & $\begin{array}{l}\text { Investigar a } \\
\text { relação ética } \\
\text { e educação } \\
\text { nos cursos } \\
\text { de enferma- } \\
\text { gem e assis- } \\
\text { tência social }\end{array}$ & $\begin{array}{l}\text { 14\% dos participantes não tive- } \\
\text { ram educação ética. Aqueles com } \\
\text { educação ética, profissional ou } \\
\text { continuada, mostraram-se mais } \\
\text { confiantes em seus julgamentos } \\
\text { morais e propensos a usar fer- } \\
\text { ramentas da ética no cotidiano } \\
\text { profissional. Os assistentes sociais } \\
\text { tiveram educação mais global, } \\
\text { voltada à ética, tendendo a usar } \\
\text { mais esse recurso do que os en- } \\
\text { fermeiros. }\end{array}$ \\
\hline 7 & $\begin{array}{c}\text { África do } \\
\text { Sul }\end{array}$ & Graduação & Pública & Qualitativa & $\begin{array}{l}\text { Conhecer o } \\
\text { programa de } \\
\text { ética médica } \\
\text { da Faculdade } \\
\text { de Ciências } \\
\text { da Saúde }\end{array}$ & $\begin{array}{c}\text { Concluiu que o programa de ética } \\
\text { médica da universidade é defi- } \\
\text { ciente e que a implementação de } \\
\text { currículo de base para todas as } \\
\text { escolas médicas na África do Sul } \\
\text { iria melhorar significativamente } \\
\text { os objetivos da educação médica } \\
\text { no país. }\end{array}$ \\
\hline 8 & Lituânia & Mestrado & Pública & Qualitativa & $\begin{array}{c}\text { Investigar a } \\
\text { experiência } \\
\text { de ensino } \\
\text { da ética em } \\
\text { programa } \\
\text { de mestrado } \\
\text { em Saúde } \\
\text { Pública e } \\
\text { discutir seu } \\
\text { conteúdo, } \\
\text { habilidades, } \\
\text { abordagens } \\
\text { de ensino e } \\
\text { ferramentas }\end{array}$ & $\begin{array}{c}\text { Evidenciou uma série de desafios } \\
\text { para o ensino de ética na Lituânia. } \\
\text { Demonstrou que o assunto é ne- } \\
\text { cessário para profissionais de saú- } \\
\text { de em treinamento. Considerou } \\
\text { que o ensino da ética em saúde } \\
\text { pública pode ajudar a melhorar } \\
\text { a capacidade dos trabalhadores } \\
\text { de saúde para tomarem a melhor } \\
\text { decisão ética em suas complexas } \\
\text { situações profissionais. }\end{array}$ \\
\hline 9 & $\begin{array}{l}\text { Reino } \\
\text { Unido }\end{array}$ & Graduação & $\begin{array}{l}\text { Pública } \\
\text { (Kings } \\
\text { College } \\
\text { London } \\
\text { School of } \\
\text { Medicine) }\end{array}$ & Qualitativa & $\begin{array}{l}\text { Percepção } \\
\text { dos alunos } \\
\text { de gradua- } \\
\text { ção em me- } \\
\text { dicina sobre } \\
\text { educação } \\
\text { ética }\end{array}$ & $\begin{array}{l}\text { A maioria dos estudantes indicou } \\
\text { preferir palestras e pequenos } \\
\text { grupos de estudos para promover } \\
\text { os debates e discussões sobre a } \\
\text { ética. Concluiu-se que a ética e a } \\
\text { lei de ensino devem ser melhor } \\
\text { abordadas em currículo. }\end{array}$ \\
\hline 10 & Brasil & $\begin{array}{c}\text { Pós- } \\
\text { graduação }\end{array}$ & $\begin{array}{l}\text { Pública e } \\
\text { privada }\end{array}$ & $\begin{array}{l}\text { Qualitativa } \\
\text { (87 progra- } \\
\text { mas de pós- } \\
\text { graduação } \\
\text { em Odonto- } \\
\text { logia) }\end{array}$ & $\begin{array}{l}\text { Avaliar o } \\
\text { ensino da } \\
\text { bioética nos } \\
\text { programas } \\
\text { de pós-gra- } \\
\text { duação em } \\
\text { Odontologia } \\
\text { no Brasil }\end{array}$ & $\begin{array}{c}\text { Os resultados alertam os educa- } \\
\text { dores envolvidos em ensino da } \\
\text { pesquisa odontológica. Mostram } \\
\text { que a instrução em bioética ainda } \\
\text { é incipiente nos programas de } \\
\text { pós-graduação em Odontologia } \\
\text { no Brasil. Por este motivo, seria } \\
\text { necessário assegurar uma peda- } \\
\text { gogia ética na formação do jovem } \\
\text { pesquisador. } \\
\end{array}$ \\
\hline
\end{tabular}




\begin{tabular}{|c|c|c|c|c|c|c|}
\hline Art. & País & $\begin{array}{l}\text { Nível de } \\
\text { ensino }\end{array}$ & $\begin{array}{l}\text { Universi- } \\
\text { dade }\end{array}$ & Metodologia & Objetivos & Resultados \\
\hline 11 & Brasil & Graduação & $\begin{array}{l}\text { Não se } \\
\text { aplica }\end{array}$ & \begin{tabular}{|c|} 
Revisão in- \\
tegrativa de \\
artigos cientí- \\
ficos sobre o \\
ensino da éti- \\
ca nos cursos \\
de saúde \\
\end{tabular} & $\begin{array}{l}\text { Analisar o } \\
\text { ensino da } \\
\text { ética nos } \\
\text { cursos de } \\
\text { graduação } \\
\text { da área da } \\
\quad \text { saúde }\end{array}$ & $\begin{array}{c}\text { Indicou que o tempo de exposi- } \\
\text { ção ao conteúdo e sua transver- } \\
\text { salidade nas disciplinas do curso } \\
\text { influenciam mais intensamente } \\
\text { a aprendizagem da ética, assim } \\
\text { como a formação e a atitude ética } \\
\text { do docente. }\end{array}$ \\
\hline 12 & Brasil & Graduação & $\begin{array}{l}\text { Não se } \\
\text { aplica }\end{array}$ & $\begin{array}{l}\text { Artigo de } \\
\text { reflexão }\end{array}$ & $\begin{array}{c}\text { Reflexão so- } \\
\text { bre aspectos } \\
\text { filosóficos } \\
\text { e sociais do } \\
\text { ensino da } \\
\text { ética/bioé- } \\
\text { tica para o } \\
\text { desenvolvi- } \\
\text { mento moral } \\
\text { dos alunos } \\
\text { de enferma- } \\
\text { gem na gra- } \\
\text { duação }\end{array}$ & $\begin{array}{c}\text { Propõe redirecionar o ensino } \\
\text { da ética em enfermagem de um } \\
\text { enfoque deontológico centrado } \\
\text { em discussões conceituais para } \\
\text { o ensino transversal de valores, } \\
\text { por meio de metodologias ativas. } \\
\text { Exige de todos os envolvidos no } \\
\text { processo ensino-aprendizagem } \\
\text { postura inovadora, que desen- } \\
\text { cadeie novas práticas. Ressalta } \\
\text { a necessidade de se enfrentar o } \\
\text { ensino metafísico da ética e da } \\
\text { bioética administrando cursos } \\
\text { diferentes e posturas que levem } \\
\text { ao planejamento e implementa- } \\
\text { ção de projetos de educação em } \\
\text { enfermagem para que integre o } \\
\text { ensino à realidade. }\end{array}$ \\
\hline
\end{tabular}

